Contents List available at RAZI Publishing

Acta Informatica Malaysia(AIM)

Journal Homepage: http://www.razipublishing.com/journals/acta-informatica-malaysia

https://doi.org/10.26480/aim.01.2017.10.11

\title{
Claim Management System
}

Ong Lee Wah ${ }^{1}$, Rohayanti Hassan ${ }^{1}$, Shahreen Kasim ${ }^{2}$, Mohd Farhan Md Fudzee², Azizul Azhar Ramli², Hairulnizam Mahdin²,

Seah Choon Sen ${ }^{2}$

${ }^{1}$ Department of Software Engineering, Faculty of Computing, Universiti Teknologi Malaysia, 81310 Johor Bharu, Johor, Malaysia

${ }^{2}$ Faculty of Computer Science and Information Technology University Tun Hussein Onn Malaysia Parit Raja, 86400 Batu Pahat, Johor, Malaysia

kellaong93@hotmail.com, rohayanti@utm.my, \{azizulr, shahreen, farhan, aizi\}@uthm.edu.my, seanseah0702@gmail.com

This is an open access article distributed under the Creative Commons Attribution License, which permits unrestricted use, distribution, and reproduction in any medium, provided the original work is properly cited.

\section{ARTICLE DETAILS}

Article history:

Received 22 January 2017

Accepted 03 February 2017

Available online 05 February 2017

Keywords:

Claim Management, Mileage Claim, Overtime Work Claim

\section{ABSTRACT}

MBJB Claim Management System is developed to provide an online platform for MBJB staff to manage the claim activities. By changing the current manual claim method to computerised system, the effectiveness and efficiency of claim process have been improved, for instances this system can quicken the approval process as well as allow applicants to check the status of claim application, minimizes human errors in calculation and provides several type of claim report. By putting the system online, there is no more problems of time and distance. Iterative Model which each iterative are mini-waterfall is applied to develop this project. Furthermore, Model-View-Controller (MVC) architecture is also used for developing this project. Hence, laravel framework is used. Data dictionary is produced for better understanding on system database. Several user interfaces are created to visualise the actual system environment. Last but not least, Hypertext pre-processor (PHP), Javascript, jQuery and MySQL are used during system development. As a conclusion, MBJB Claim Management system can replace the existing manual claim management as well as bring benefits to staff MBJB.

\section{Introduction}

Overtime is defined as time worked beyond officer's scheduled working hours. Most of the workers have the experiences in overtime work. To claim for overtime work pay, they need to fill in claims application form by hand. Errors can be made when the worker filling in the application form. The accountant may make mistakes when counting for the total claims. Meanwhile, the workers are unable to know the status of application immediately and they are only able to know the status by checking whether the claim amount is bank in to their bank account. The same problem goes to the mileage claim where there are a few things to be taken into consideration, for example, transport type and total mileage.

This project is about developing a claim management system that can improve the performance of claiming process by letting the staff apply for mileage claim and overtime work claim online and the system will automatically calculate the total claims. A worker shall not claim for overtime work that exceed one third of monthly salary per month. A worker is able to view their status instantly. Hence, if there is any rejected claim application, a worker can edit the claim record immediately. Having a system that records the claim history may help them to calculate the accumulative claims amount. The financial manager is able to make further budget decision by viewing the report generated by the system.

The system has been designed and illustrates using UML diagrams such as use case diagram, sequence diagram and activity diagram based on the analysed requirement. This project uses the laravel framework which implements the Model View Controller (MVC) architecture. This project is mainly written in PHP javascript, jQuery and AJAX.

\section{Objectives}

There are four objectives in this project, which are:

i. To analyze the requirements for application of mileage claim and overtime work claim.

ii. To design and develop claim management system for MBJB enforcement staff that may improve the efficiency of the claim management.

iii. To test claim management system based on User Acceptance Test.

\section{Methodology}

Instead of waterfall model, iteration model is more flexible. Govardhan and Nabil (2010), stated in their journal "A Comparison between Five Models of Software Engineering" that iteration model (as shown in figure 1) is an approach that divides the system into several small chunks and each chunk is known as iteration / module. Each iteration is a mini-waterfall process, so developer doesn't require to acquire all requirement in one time which may causes the delaying of the progress. As result, iteration model allows developers to obtain the result faster as well as get feedbacks from stakeholders earlier compare to normal waterfall process model.

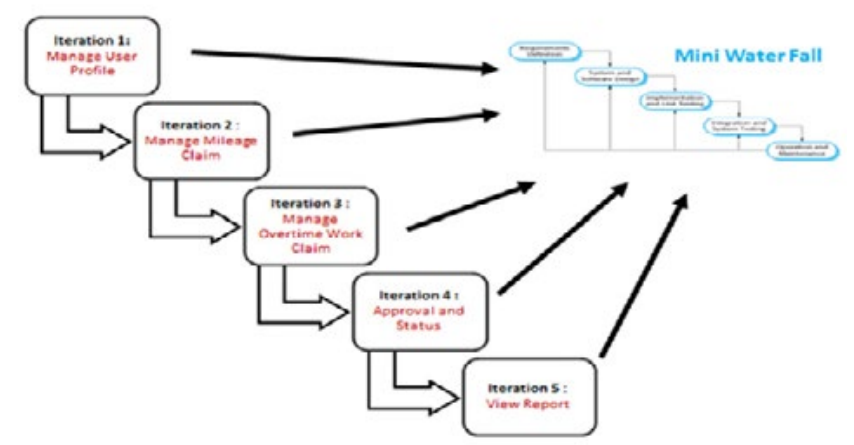

Figure 1 Iteration Model

4. Result

The use case diagram of developed system is shown in Figure 2.

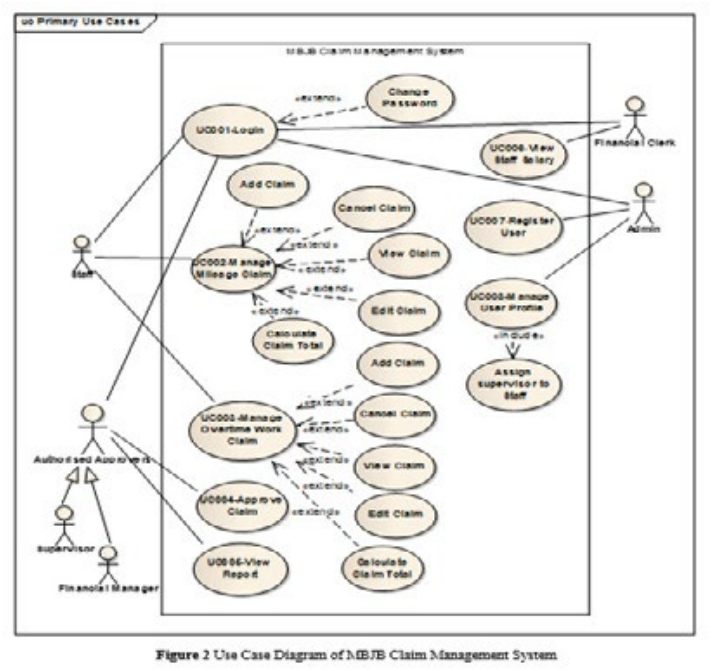

Figure 2 Use Case Diagram of MBJB Claim Management System

Below are some of the user interfaces of the MBJB Claim Management System. 


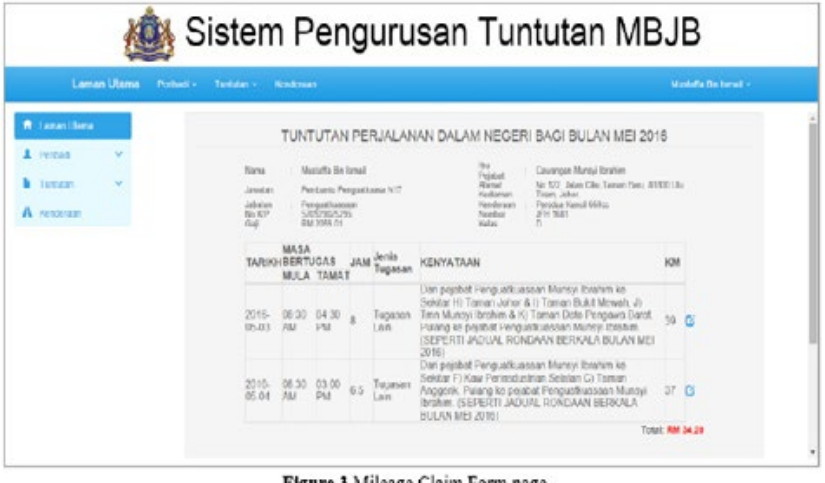

Figure 3 Mileage Claim Form page

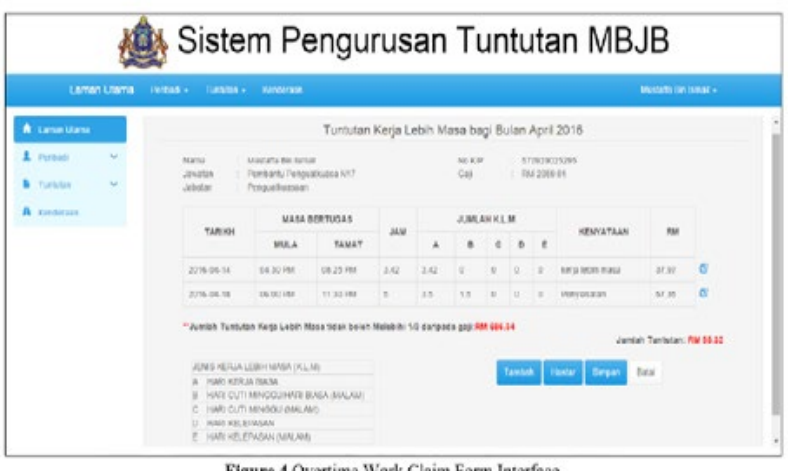

Figure 4 Overtime Work Claim Form Interface

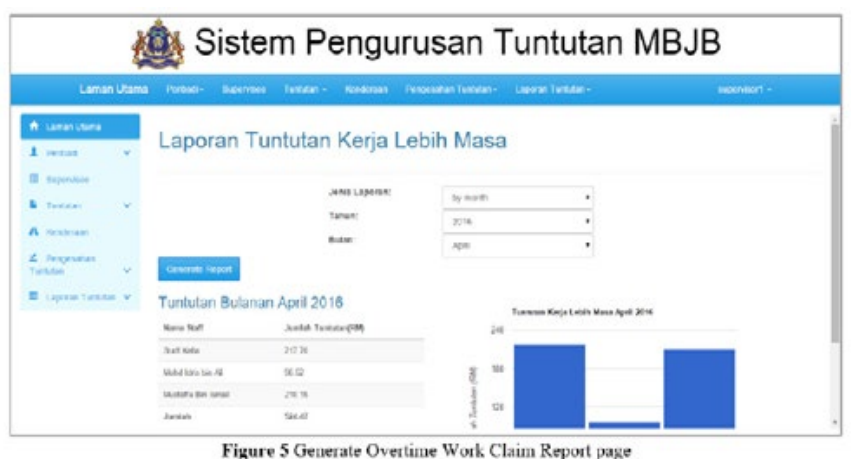

\section{Discussion}

All of the objectives of Claim Management System have been achieved and explained in Table 1.

\begin{tabular}{|c|c|}
\hline Objectives & Achuevements \\
\hline $\begin{array}{l}\text { i. To analyse the requirements for } \\
\text { application of mileage claim and } \\
\text { overtime work claim. }\end{array}$ & $\begin{array}{l}\text { An interview session bas been conducted with a MBJB enforcement } \\
\text { staff, which has provided the problems facing as of the current } \\
\text { system as well as the requirement for this system. From the } \\
\text { interview session, it can be coucluded that be current manual } \\
\text { system is time-consuning and there might have calculations mistake } \\
\text { on claim amonat. }\end{array}$ \\
\hline $\begin{array}{l}\text { ii. To design and develop claim } \\
\text { management system for MBJB } \\
\text { enforcement staff that may improve } \\
\text { the efficiency of the claim } \\
\text { management. }\end{array}$ & $\begin{array}{l}\text { The system is using Iteration Model as the process model and MVC } \\
\text { architecture for system aschitectural design. Requirements of the } \\
\text { system are drawn using UML and database have been designed. } \\
\text { Enterprise Architecture is used for design purpose. } \\
\text { The main programing language that used to develop the system is } \\
\text { PHP, jQuery and AJAX. The softvare used to build the system is } \\
\text { Jetsbrains phpStorm 7.1.3. Laravel framework is used for } \\
\text { development. All the use cases have successfully developed in the } \\
\text { system. }\end{array}$ \\
\hline $\begin{array}{l}\text { iii. To test chim management system } \\
\text { hased on User Acceptance Test }\end{array}$ & User Acceptance Testing is done and documented. \\
\hline
\end{tabular}

\section{Conclusion}

Claim Management System is a web-based system that is used to manage travel claim and overtime work claim. An enforcement staff can make travel claim application and overtime work claim. A supervisor can verify staff's claim and a financial manager can approve staff's claim. Financial clerk is able to view staff salary to proceed on salary payment. Furthermore, supervisor and financial managers are able to generate reports. The system has shorten the process and time for claims application and approval.

\section{References}

1. Ali Munassar, N. M., \& Govardhan, A. (2010). A Comparison Between Five Models of Software Engineering. (IJCSI) International Journal of Computer Science Issues, 7, 94-101 